\title{
The Role of Impulse Control Disorders in Assessing Criminal Responsibility: Medico-Legal Perspectives from South Africa
}

\author{
Geert Philip Stevens* \\ Department of Public Law, University of Pretoria \\ *Email: philip.stevens@up.ac.za
}

\begin{abstract}
The role of impulse control disorders on criminal responsibility is currently a controversial issue. With the advent of the DSM-5 various questions arise which specifically relate to the nature and impact of impulse control disorders on criminal responsibility. Further anomalies, in addition, relate to the differences between the classification of impulse control disorders in the DSM-IV-TR as opposed to the recent DSM-5. To date the issue of impulse control disorders has only been addressed in limited criminal case law in South Africa and indicates that courts generally view these disorders as mitigating factors during the sentencing procedure. The focus of this contribution will be to revisit the diagnostic framework for impulse control disorders with specific reference to the criteria provided for in the DSM-5 in order to assess its applicability to a finding of diminished criminal responsibility as provided for in section 78(7) the Criminal Procedure Act 51 of 1977, and whether it could in certain circumscribed circumstances fulfil the criteria for the defence of pathological criminal incapacity, or more commonly known as the insanity defence. The vital and essential role of the mental health expert within such context will be illustrated.
\end{abstract}

Key words: criminal incapacity, diminished criminal capacity, impulse control disorders

There is a partial insanity of mind ...; some persons that have a competent use of reason in respect of some subjects, are yet under a particular dementia in respect of some particular discourses, subjects or applications; or else it is partial in respect of degrees; and this is the condition of very many, especially melancholy persons, who for the most part discover their defect in excessive fears or griefs, and yet are not wholly destitute of the use of reason; and this partial insanity seems not to excuse them in the committing of any offence for its matter of capital; for doubtless most persons, that are felons of themselves, and others are under a degree of partial insanity when they commit these offences. ${ }^{1}$

\section{Introduction}

Sylvia is a thirty-six year old single female. Since late adolescence she has had a history of uncontrollable shoplifting. As time progressed she became obsessed with stealing, thinking about it all the time. Initially it started when she stole candy with friends, but later it developed into a daily need to steal by herself. Sylvia currently shoplifts one to two times per week and experiences a 'high' each time. Sylvia mainly steals hygiene products such as shampoo and soap. She prefers to use the stolen items and states that having these items comforts her. Sylvia recalls daily thoughts and urges to shoplift and reports that it consumes 
her thoughts for up to three to four hours each day. Sylvia often leaves work early in order to get to a store to steal something. Sylvia states that she feels compelled to shoplift items. ${ }^{2}$ The facts regarding Sylvia serve to set the stage for the theme of this contribution which deals with the assessment of criminal responsibility in cases where the accused suffered from an impulse control disorder at the time of the commission of the offence. Within the context of South African criminal law the appropriate defence that an accused will invoke in such a scenario would be the defence of pathological criminal incapacity, often referred to as the 'insanity' defence. This contribution will reflect on the consequential impact of such defence where reliance is placed on the presence of impulse control disorders at the time of the commission of the offence, in support of such defence.

The interface between criminal law and the field of psychiatry and to a lesser extent, psychology, has manifested predominantly in pathological criminal incapacity or, described differently, criminal non-responsibility attributable to mental illness. ${ }^{3}$

The defence of criminal incapacity is primarily and exclusively concerned with the human mind and the human psyche. Few things are so complex and difficult to comprehend as the human mind, controlling human behaviour. The interplay between law and medicine with specific reference to the fields of psychiatry and psychology is fundamentally rooted in the defence of pathological criminal incapacity. In cases where the defence of pathological criminal incapacity is raised, the Criminal Procedure Act provides for a panel of three psychiatrists and a clinical psychologist to evaluate, observe and report on the mental status of the accused. ${ }^{4}$

One of the primary sources of conflict between psychiatry and criminal law in cases where pathological criminal incapacity is raised relates to the definition of 'mental illness' or 'mental defect'. In order to establish the defence of pathological criminal incapacity, it has to be proved that the accused at the time of committing the offence suffered from a 'mental illness' or 'mental defect' which rendered him or her incapable of appreciating the nature and/or wrongfulness of his or her act or omission and/or acting in accordance with such appreciation of wrongfulness. The threshold requirement for pathological criminal incapacity is thus 'mental illness or defect'.

The problem with the current defence of pathological criminal incapacity is that it does not specifically identify the mental disorders which could constitute a 'mental illness' or 'mental defect'. The defence only provides for the specific effects that must result from a particular 'mental illness' or 'mental defect'. This problem is exacerbated by the fact that the term 'criminal incapacity' is a legal term and not a medical one. ${ }^{5}$ The question which remains to be considered is whether criminal law and psychiatry should not work together rather than against one another where the defence of pathological criminal capacity is raised. The human mind and psyche remain complex and difficult to analyse. Should the assessment and definition of 'mental illness' not be left to the medical profession?

Stone correctly states that extreme forms of mental illness, for example schizophrenia, pose fewer challenges to the legal system than the so-called 'grey zone', where milder disorders and personality disorders can be traced. These milder disorders present enormous 
challenges to the legal profession. ${ }^{6}$ Impulse control disorders, it is submitted, could very well fall within the latter category of disorders posing various challenges to the legal system.

During the assessment of mental disorders, use is made of the DSM $-5 .^{7}$ The DSM- 5 as well as its predecessors includes a cautioning statement warning against its usage in legal context in respect of the diagnoses set forth in the manual. The DSM-5 provides the following caveat: ${ }^{8}$

Although the DSM-5 diagnostic criteria and text are primarily designed to assist clinicians in conducting clinical assessment, case formulation, and treatment planning, DSM-5 is also used as a reference for the courts and attorneys in assessing the forensic consequences of mental disorders. As a result, it is important to note that the definition of mental disorder included in DSM-5 was developed to meet the needs of clinicians, public health professionals, and research investigators rather than all of the technical needs of the courts and legal professionals. It is also important to note that DSM-5 does not provide treatment guidelines for any given disorder.

When used appropriately, diagnoses and diagnostic information can assist legal decision makers in their determinations. For example, when the presence of a mental disorder is the predicate for a subsequent legal determination (e.g., involuntary civil commitment), the use of an established system of diagnostic enhances the value and reliability of the determination. By providing a compendium based on a review of the pertinent clinical and research literature, DSM-5 may facilitate legal decision makers' understanding of the relevant characteristics of mental disorders. The literature related to diagnoses also serves as a check on ungrounded speculation about mental disorders and about the functioning of a particular individual. Finally, diagnostic information about longitudinal course may improve decision making when the legal issue concerns an individual's mental functioning at a past or future point in time.

However, the use of DSM- 5 should be informed by an awareness of the risks and limitations of its use in forensic settings. When DSM- 5 categories, criteria, and textual descriptions are employed for forensic purposes, there is a risk that diagnostic information will be misused or misunderstood. These dangers arise because of the imperfect fit between the questions of ultimate concern to the law and the information contained in a clinical diagnosis. In most situations, the clinical diagnosis of a DSM-5 mental disorder such as intellectual disability (intellectual developmental disorder), schizophrenia, major neurocognitive disorder, gambling disorder, or paedophilic disorder does not imply that an individual with such a condition meets legal criteria for the presence of a mental disorder or a specified legal standard (e.g., for competence, criminal responsibility, or disability). ${ }^{9}$ For the latter, additional information is usually required beyond that contained in the DSM-5 diagnosis, which might include information about the individual's functional impairments and how these impairments affect the particular abilities in questions. It is precisely because impairments, abilities, and disabilities vary widely within each 
diagnostic category that assignment of a particular diagnosis does not imply a specific level of impairment or disability.

This caveat clearly denotes both the so-called 'grey zone' disorders such as paedophilia, as well as a 'gap' between law and medicine. The problem with this cautionary statement is that an accused may suffer from a mental illness recognised in terms of clinical diagnostic criteria, yet such mental illness may perhaps fall short of the benchmark required to satisfy the legal criterion. The latter is further exacerbated by the fact that there has to be a causal nexus between the alleged mental illness an accused suffers or suffered from and the commission of the offence.

Within the ambit of the defence of pathological criminal incapacity, the question to be assessed is whether an accused who commits an offence as a result of suffering from one or more of the impulse control disorders listed in the DSM-5 will be able to invoke the defence of pathological criminal incapacity. A related question to be determined is whether impulse control disorders, and the diagnostic criteria determined for each, will be sufficient to exonerate an accused of criminal responsibility or whether such disorders will merely serve to mitigate sentence and as such only play a role for purposes of establishing diminished criminal capacity. In this contribution the author will address the mental disorders clustered under the tag of impulse control disorders in conjunction with their distinctive diagnostic features against the backdrop of the defence of pathological criminal incapacity within the South African context.

\section{Impulse Control Disorders of Legal Significance}

According to Moeller et al, impulsivity is described as a predisposition toward rapid, unplanned reactions to either internal or external stimuli in disregard of any negative consequences. ${ }^{10}$ In terms of the DSM-IV and the DSM-IV-TR, the category of Impulse Control Disorders Not Elsewhere Specified provides for the cluster of impulse control disorders which include pathological gambling, kleptomania, trichotillomania, pyromania, intermittent explosive disorder as well as impulse control disorders not otherwise specified. ${ }^{11}$ Interestingly, pathological gambling was subsequently removed from the cluster in the DSM-5 and included in the section dealing with Substance Related and Addictive Disorders. ${ }^{12}$ The latter disorder was, in addition, renamed and is now labelled as gambling disorder. The most essential feature of impulse control disorders relates to the fact that they all require some pathological inability to resist internal 'impulses'. ${ }^{13}$

According to Stoll, impulsivity is conceptualised as being 'the antithesis of compulsivity'. ${ }^{14}$ Stoll describes the latter as follows: ${ }^{15}$

Compulsive people are highly risk-averse, they engage in destructive ritualistic activity because they believe it will ward off some perceived harm. Dispositionally impulsive people, meanwhile - persons who might be classified as suffering from an impulse control disorder - engage in high-risk behaviour because it gratifies their internal wants and desires and relieves their intense urges. 
In order to assess the impact of impulse control disorders on criminal responsibility properly, it is essential to disseminate the disorders. It is notable that the DSM-IV-TR lists the impulse control disorders under the heading 'Impulse Control Disorders Not Elsewhere Classified' and this category provides for the disorders known as intermittent explosive disorder, kleptomania, pyromania, pathological gambling and trichotillomania. ${ }^{16}$ The DSM-5, however, includes impulse control disorders under the heading 'Disruptive, Impulse-Control and Conduct Disorders' which provides for the disorders known as oppositional defiant disorder, intermittent explosive disorder, conduct disorder, antisocial personality disorder, pyromania and kleptomania. ${ }^{17}$ Pathological gambling as provided for in the DSM-IV-TR was removed from the section dealing with impulse control disorders and included in the section dealing with 'Substance-Related and Addictive Disorders'. ${ }^{18}$ For the purposes of the current contribution, the following impulse control disorders will be addressed as the most significant disorders which could become relevant in respect of the defence of pathological criminal incapacity or diminished criminal capacity: ${ }^{19}$

- Pathological gambling versus gambling disorder;

- Intermittent explosive disorder;

- Pyromania;

- Kleptomania

\subsection{Pathological Gambling Versus Gambling Disorder}

According to the DSM-IV-TR the essential characteristic of pathological gambling consists of the 'persistent and recurrent maladaptive behaviour that disrupts personal, family, or vocational pursuit'. ${ }^{20}$ In such circumstances the individuals are preoccupied with gambling and report that they seek 'action' or 'excitement' more than money. ${ }^{21}$ The individual may resort to gambling as a manner of escaping from problems or to relieve feelings of helplessness, anxiety or depression. ${ }^{22}$ Pathological gambling is typified by long-term chase rather than gambling for shorter periods. ${ }^{23}$ Individuals suffering from pathological gambling may resort to antisocial behaviours such as forgery, fraud, theft or embezzlement when resources are low. ${ }^{24}$ Individuals suffering from pathological gambling often display distorted thoughts and frequently believe that money will be the solution to any problem. ${ }^{25}$ In terms of criminal behaviour associated with pathological gambling, Grant opines as follows: ${ }^{26}$

Many pathological gamblers engage in illegal behaviour, such as stealing, embezzlement, and writing bad checks to fund their gambling or in an attempt to pay off past gambling losses.

The DSM-5 has changed the face of pathological gambling by including it within the cluster of addictive disorders. Frances notes that the latter could prove to be problematic and states the following: $:^{27}$

DSM-5 accords Pathological Gambling the honor of its own section as the first Behavioral Addiction. In contrast, I have instead chosen to keep Pathological Gambling in its traditional place among the Impulse Control Disorders. The creation of a category especially for Behavioral Addictions is likely to open the Pandora's box of Unspecified Behavioral Addictions. I can picture this leading to the expansion of 
psychiatry to encompass a wide variety of life's pleasures and passions better left outside its purview - shopping, internet surfing, video games, sex, exercise, collecting, sunbathing and perhaps even model railroading.

The diagnostic features of gambling disorder provided for in the DSM-5 more or less correspond with the criteria for pathological gambling. It is, however, notable that the criterion 'has committed illegal acts such as forgery, fraud, theft, or embezzlement to finance gambling' as provided for in the DSM-IV-TR has been omitted in terms of the criteria provided for in the DSM $-5 .{ }^{28}$ The latter feature is strange as the DSM- 5 has included in the discussion pertaining to the diagnostic features associated with gambling disorder the statement that individuals may often be deceitful in terms of covering up illegal activities including forgery, fraud, theft or embezzlement in the search for money to fund their gambling efforts. ${ }^{29}$ Save for the name change and the different category under which pathological gambling is classified, there are a few other significant differences between pathological gambling as provided for in the DSM-IV-TR as opposed to gambling disorder enunciated in the DSM-5. According to the American Psychiatric Association, the reclassification of gambling disorder reflects the fact that little evidence exists portraying the association between gambling disorder and the other impulse control disorders. ${ }^{30}$ The DSM-5, in addition, changed the time period within which symptoms should occur and requires 'persistent and recurrent problematic gambling behaviour leading to clinically significant impairment or distress as indicated by the individual exhibiting four (or more) of the nine criteria in a 12 -month period' ${ }^{31}$ The DSM-5 further changed the language of some of the remaining diagnostic criteria by changing, for example, the phrase 'preoccupied with gambling' to 'often preoccupied with gambling'. ${ }^{32}$ It is nevertheless clear that pathological gambling as well as the current category of gambling disorder can give rise to criminal behaviour. The question that ultimately arises relates to the impact of this disorder on the criminal responsibility of an offender.

\subsection{Intermittent Explosive Disorder}

Intermittent explosive disorder is typified by recurrent serious outbursts of aggression often resulting in criminal behaviours such as assault or damage to property. ${ }^{33}$ The impulsive aggressive outbursts in terms of intermittent explosive disorder have a rapid onset and typically last no longer than thirty minutes, frequently occurring in reaction to some minor form of provocation. ${ }^{34}$ Individuals usually experience less severe episodes in between more severe and destructive episodes. ${ }^{35}$ These aggressive outbursts range from temper tantrums, verbal arguments or fights to assaults, often without damage to property or injury to animals. ${ }^{36}$

Infrequent aggressive outbursts could include damaging or destroying an object or property, or assault causing injury either to another person or to an animal. ${ }^{37}$ The essential feature of intermittent explosive disorder entails failure to control impulsive aggressive behaviour in response to provocation. These outbursts are generally impulsive and not planned or premeditated. ${ }^{38}$ In terms of functional consequences of intermittent explosive behaviour, the DSM-5 specifically mentions that it could give rise to criminal behaviour. ${ }^{39}$ 


\subsection{Pyromania}

The core feature of pyromania relates to the presence of multiple instances of deliberate and purposeful fire setting. ${ }^{40}$ Individuals with this disorder experience intense fascination and attraction to fire and such fire setting is not done for financial gain, to conceal criminal activities, express anger or in response to a delusion or hallucination. ${ }^{41}$ These individuals are often indifferent to the effect or consequences to life or property as a result of the fire and may even experience satisfaction from the property destruction. ${ }^{42}$

\subsection{Kleptomania}

The essential feature of kleptomania entails the repeated failure to resist impulses to steal items despite the fact that these items are not needed for personal use or for financial gain. ${ }^{43}$ Individuals do not steal the items as a result of expressing anger or vengeance or whilst experiencing a delusion or hallucination, and usually these thefts are not preplanned. ${ }^{44}$ According to the DSM-V persons with kleptomania generally attempt to resist the impulse to steal and are aware that their conduct is wrong. ${ }^{45}$ The DSM-5, in addition, states that this disorder may have legal consequences. ${ }^{46}$

\section{A Conceptual Analysis of the Defence of Pathological Criminal Incapacity}

Within the South African context the defence of pathological criminal incapacity is embodied and as such defined in Section 78(1) of the CPA. ${ }^{47}$ Section 78(1) of the CPA provides that an accused is not criminally responsible for an act or omission which constitutes an offence if at the time of the commission of the alleged offence the accused suffered from a mental illness or mental defect which rendered him or her incapable of appreciating the wrongfulness of his or her act; or of acting in accordance with an appreciation of the wrongfulness of his or her act. ${ }^{48}$ According to Snyman, the test for pathological criminal incapacity consists of a pathological or biological leg which entails that the accused should have suffered from a mental illness or mental defect at the time of the commission of the offence; and a psychological leg which entails that the accused should have, as a result of a mental illness or mental defect, lacked the capacity of appreciating the wrongfulness of the act or of acting in accordance with such appreciation. ${ }^{49}$ The test applied is accordingly a so-called 'mixed' test in that both the pathological as well as the psychological factors are taken into account in determining whether an accused lacked criminal capacity. ${ }^{50}$

The threshold requirement for the defence of pathological criminal incapacity is the existence of a mental illness or mental defect at the time of the commission of the act. The latter requirement is also referred to as the pathological leg of the test for criminal responsibility. The particular mental illness or mental defect must in addition render the accused incapable of appreciating the wrongfulness of his or her act, or acting in accordance with an appreciation of the wrongfulness of the act. ${ }^{51}$ The latter two defences apply in the alternative. Snyman as well as Burchell and Milton opine that 'wrongfulness' for purposes of the appreciation of the wrongfulness of an act should denote either legal wrongfulness or moral wrongfulness. ${ }^{52}$ 
In respect of the defence of pathological criminal incapacity it is important to note that certain mental illnesses may not necessarily affect an accused's capacity to appreciate the wrongfulness of his or her action, but may nevertheless deprive the accused of the ability to control conduct or to act in accordance with the appreciation of wrongfulness. ${ }^{53}$ Section 78(1)(b) of the CPA accordingly provides that even though an accused was capable of appreciating the wrongfulness of his or her act, he or she will still not be criminally responsible if, at the time of the commission of the act, he or she suffered from a mental illness which rendered him or her incapable of acting in accordance with such appreciation. Africa notes that in order to rely on this defence, it has to be proved that the symptoms of the disorder resulted in a significant impairment of psychological functioning. ${ }^{54}$ It is specifically in respect of the latter realm where impulse control disorders could become relevant.

Constructing a defence of pathological criminal incapacity due to impulse control disorders will accordingly entail firstly establishing a particular impulse control disorder as a mental illness for purposes of $s$ 78(1) as a threshold requirement. It will then have to be established that such an impulse control disorder resulted in either the inability of the accused of appreciating the wrongfulness of his or her actions (cognitive capacity) or the inability of acting in accordance with the appreciation of wrongfulness (conative capacity). If the cognitive or conative capacity of the accused was sufficiently impaired as a result of a mental illness or mental defect, the accused is said to have lacked criminal capacity. ${ }^{55}$

The test for pathological criminal incapacity or insanity does not define the terms 'mental illness' or 'mental defect' nor does it specify the particular mental disorders that constitute 'mental illness' or 'mental defect'. What becomes evident is that the test only identifies the effects which should result from a particular 'mental illness' or 'mental defect'. The pivotal role of the mental health professional in the definition and assessment of the mental illness becomes evident. A question which frequently arises is whether the definition of mental illness should be a medical or a legal prerogative. Slovenko pertinently encapsulates the dilemma as follows:

During the past two centuries the courts have often said that the term 'disease of the mind' or 'mental disease or defect' in the test of criminal responsibility is not a medical but a legal term. At the same time, however, since medical or psychiatric opinion is necessary to give meaning to the term, it becomes a fusion of legal and medical components. To be sure, no rule of law can be reliable when absolutely dependent on another discipline, but without input from other areas, the law would just be amid verbal agonizing. ${ }^{56}$

The definition of mental illness should neither be solely a medical prerogative, nor exclusively a legal prerogative; the professions of law and medicine with specific reference to forensic psychiatry should meet one another halfway in the assessment of mental illness for purposes of the defence of pathological criminal incapacity. The fact remains - the law needs medicine to provide meaning to the defence of insanity and accordingly medical input in the assessment of insanity is pivotal if not essential. The latter inadvertently also applies to impulse control disorders. The presence or absence of impulse control disorders can only be assessed by adequately trained mental health professionals. In respect of expert 
evidence by mental health professionals, a court is obliged in terms of Section 78(2) of the CPA to refer an accused for observation if it is alleged at criminal proceedings that an accused is by reason of mental illness or mental defect not criminally responsible or if it appears to the court that an accused is for such a reason not criminally responsible. The matter is then enquired into and reported on in accordance with s 79 of the CPA which provides for the panel of experts who are required to conduct the assessment and comply with the procedural aspects associated therewith. The latter sections will accordingly inadvertently also apply to an accused alleging that he or she committed an offence as a result of suffering from impulse control disorders. An in-depth analysis of the terms 'mental illness' and 'mental defect' falls beyond the scope of this contribution.

\section{Impulse Control Disorders within the Context of Sentencing - Reflections from South African Case Law}

The only impulse control disorder that has featured in South African criminal case law is pathological gambling. The latter was, in addition, only addressed in two decisions. It is notable that in neither of the two decisions the accused relied on the defence of pathological criminal incapacity as a defence. Reliance was only placed on the particular impulse control disorder in support of mitigation of sentence. In Wasserman $v S^{57}$ the facts were that the appellant was charged with 64 counts of theft involving over one million rand. She was consequently convicted on all counts and was sentenced to 15 years imprisonment in terms of s 51(2)(a)(1) of the Criminal Law Amendment Act 105 of 1997. ${ }^{58}$ The latter provision provides that a person who is convicted of theft involving an amount more than R500,000 and who is a first offender must be sentenced to imprisonment for a period not less than 15 years unless there were substantial and compelling circumstances justifying a lesser sentence than the prescribed minimum sentence. The appellant appealed against her sentence and on appeal the question which had to be assessed was whether the sentence imposed in the trial court had been fair in light of the fact that the appellant had been diagnosed as suffering from pathological gambling disorder. A related question which had to be answered was whether pathological gambling qualified as a substantial and compelling circumstance in order to depart from the minimum sentence provided for in the Act. In assessing whether pathological gambling qualified as a mitigating factor, evidence was heard from Professor Schaffer, the director of the Division on Addictions at the Harvard Medical School who testified that gambling affects the central nervous system. ${ }^{59}$ Schaffer further stated the following: ${ }^{60}$

But let me just say that there is neurotransmitter activity that accompanies gambling and it is much like taking a psycho-stimulant and by psycho-stimulant I mean nicotine, caffeine, cocaine so that it is similar to those quick hitting, rapid, stimulating drugs ... The acting out are the stimulants, the gambling, risk taking behaviours. These can all hold addictive potential.

It was held by Patel J that pathological gambling constituted a progressive disease which could be effectively treated. ${ }^{61}$ In terms of assessing whether pathological gambling constituted a mitigating factor it was held by Patel $\mathrm{J}$ that addiction to gambling constituted a mitigating factor which could impact on sentencing. ${ }^{62}$ It was accordingly held by Patel J that the imposition of the prescribed minimum sentence was shockingly inappropriate. ${ }^{63}$ 
Accordingly, after regard was taken of the appellant's personal circumstances, the offence and the broader interests of the community, the sentence imposed by the trial court was set aside and replaced with a sentence of five years correctional supervision in terms of which half of the sentence was suspended for three years provided that the accused was not convicted of any crimes of attempted theft, theft, attempted fraud, fraud, attempted forgery, forgery, uttering or making false representation. ${ }^{64}$ It was further ordered that the appellant be referred for counselling and rehabilitation programmes for her pathological gambling disorder. ${ }^{65}$ The decision in Wasserman was the first judgement in which pathological gambling was recognised as a disorder and that it could constitute a substantial and compelling circumstance justifying a lesser sentence than the prescribed sentence provided for in the Act. Obviously in terms of sentencing, pathological gambling will be assessed in conjunction with all the relevant circumstances of the case in order to determine the presence or not of substantial and compelling circumstances. ${ }^{66}$

In $\mathrm{Nel} v S^{67}$ the appellant was convicted in the trial court of robbery with aggravating circumstances and was sentenced in terms of the Act to 15 years imprisonment. The salient facts were that on the morning of 19 February 1999, the appellant, armed with an unloaded firearm, went to the Lorraine Entertainment Centre in Port Elizabeth, held up the staff and then locked them in the ladies' toilet and robbed them of R32,595. He was consequently arrested and pleaded guilty. ${ }^{68}$ The appellant testified in mitigation of sentence that he had been suffering from a gambling addiction which had started as early as 1994 and which he failed to curb despite having stopped at some stage. According to his testimony, gambling had consumed him to such a degree that he was known as a regular and a 'most valued guest' at some gambling houses. ${ }^{69}$ The appellant testified that despite having generated a generous income, he became more and more indebted as a result of his gambling. ${ }^{70}$ In mitigation of sentence the appellant relied on the expert evidence of a clinical psychologist, Mr Barend Breedt. Mr Breedt testified that the appellant presented as immature and compulsive and had low self-esteem which drove him to live in a fantasy world, which in turn enabled him to compensate for those feelings and which affected his ability to make rational decisions. ${ }^{71} \mathrm{Mr}$ Breedt further testified that the appellant suffered from a personality defect manifesting in a pathological gambling problem and that the appellant had reached the third and last phase of gambling which was a disorganised phase where gambling had completely taken over his life, and that he remained a danger to society if he did not receive adequate treatment. ${ }^{72} \mathrm{Mr}$ Breedt testified that the appellant needed longterm psychological treatment to deal with his gambling addiction and accordingly that longterm imprisonment and the appellant's removal from gambling facilities without the required psychological treatment would have no effect on him. ${ }^{73}$ The trial court reasoned that as robbery with aggravating circumstances was a serious offence, it had to impose the prescribed 15 years imprisonment and accordingly that there had been no substantial and compelling circumstances present which had justified the imposition of a lesser sentence. ${ }^{74}$ On appeal it was argued on behalf of the appellant that his pathological gambling had made drastic inroads into his ability to make rational decisions and should have been viewed on its own as a mitigating factor and as such constituted a substantial and compelling circumstance which justified the imposition of a lesser sentence than the prescribed minimum sentence. ${ }^{75}$ Reliance was further placed on behalf of the appellant on the decision in Wasserman supra. ${ }^{76}$ On appeal Mlambo JA, however, criticised the approach followed in Wasserman and held as follows: ${ }^{77}$ 
In my view the reasoning in Wasserman supra was unnecessarily overbroad, and it is not surprising that the Court was unable to find support for its views in the South African jurisprudence. In my view the Court's approach was too broadly expressed as to amount to an undue relegation of the retributive and deterrent elements in sentencing in favour of the rehabilitative and reformative elements. Indeed it could open the door to undue reliance by gambling addicts on their addiction to escape an appropriate sentence in the form of direct imprisonment.

Mlambo JA further held that gambling addiction can never operate as an excuse for the commission of an offence. ${ }^{78}$

In respect of pathological gambling, Mlambo JA reasoned as follows: ${ }^{79}$

Whilst gambling addiction may be found to cause the commission of an offence, even if it is pathological (as in this case) it cannot on its own immunise an offender from direct imprisonment. Nor indeed can it on its own be a mitigating factor, let alone a substantial and compelling circumstance justifying a departure from the prescribed sentence.

It was accordingly emphasised by Mlambo JA that in order to find substantial and compelling circumstances, a broader and more holistic approach had to be followed. ${ }^{80}$ Having regard to the appellant's financial predicament he had placed himself in, caused by the gambling addiction in conjunction with other factors such as remorse, the use of an empty firearm and the lack of any physical injuries to the victims were all weighty considerations in the assessment of the presence or not of substantial and compelling circumstances. ${ }^{81}$ Having regard to all the factors mentioned above, Mlambo JA held that there were substantial and compelling circumstances present and accordingly reduced the sentence of 15 years imprisonment to 10 years imprisonment. ${ }^{82}$

Reflecting upon the judgements in Wasserman and Nel supra it is apparent that pathological gambling and consequently possibly gambling disorder as contained in the DSM-5 will be approached by the courts with caution. In terms of sentencing the court will take a holistic view of all the circumstances in order to assess as to the presence or absence of substantial and compelling circumstances. It could be argued that the court in any event applied a holistic approach as it did not solely view the pathological gambling as a substantial and compelling circumstance, but still had regard to other factors as well. It is, however, true that it was held that pathological gambling could constitute a substantial and compelling circumstance, and having regard to the fact that the Nel decision constitutes Appellate authority, it is doubtful whether on its own it would amount to a substantial and compelling circumstance. ${ }^{83}$ As Carnelley correctly submits, gambling addiction is but one of many factors to be considered during the sentencing phase. ${ }^{84}$

\section{Medicolegal Issues at Stake}

It remains an undeniable fact that whenever the defence of pathological criminal incapacity is raised, the two oceans of law and medicine meet and inevitably, clash. It was noted earlier in this contribution that the threshold requirement for establishing the defence of 
pathological criminal incapacity is the presence of a mental illness or mental defect at the time of the commission of the offence, which rendered the accused incapable either of appreciating the wrongfulness of his or her actions, or of acting in accordance with such appreciation. The diagnostic framework currently employed in the diagnosis and assessment of mental disorders is the DSM-5, yet as the cautionary statement clearly states, the DSM-5 criteria will not necessarily meet legal standards and norms, especially during the assessment for purposes of determining criminal responsibility. Impulse control disorders present a multifaceted challenge to the criminal justice system whenever the defence of pathological criminal incapacity is raised. The medicolegal obstacles associated with impulse control disorders within the ambit of the defence of pathological criminal incapacity are multi-layered. The obstacle which arises is the question as to whether impulse control disorders will be sufficient to satisfy the threshold requirement of the defence of pathological criminal incapacity - the presence of a mental illness or mental defect.

Central to the assessment of impulse control disorders for purposes of the insanity defence is the mental health professional who will be requested to conduct the forensic assessment and ultimately present expert evidence in court. A question which arises is whether evidence of impulse control disorders will be admissible and, if so, what probative value the courts will attach to such evidence. A further medicolegal challenge relates to the scientific reliability and validity of expert evidence pertaining to impulse control disorders. A major consideration in cases where persons rely on impulse control disorders in support of the defence of pathological criminal incapacity relates to risk of malingering.

Within the South African criminal law context only one of the listed impulse control disorders has featured in case law. It was, in addition, not relied upon within the context of the defence of pathological criminal incapacity. Accordingly, the impact of impulse control disorders on the defence of pathological criminal incapacity remains controversial. From the diagnostic criteria of the other impulse control disorders, it becomes clear that these disorders could very well become relevant within the context of the defence of pathological criminal incapacity. These disorders could specifically become relevant within the ambit of the second leg of the capacity enquiry dealing with whether the accused, despite his or her awareness of the wrongfulness of the act, had the capacity to act in accordance with such appreciation and accordingly whether the accused could exert the necessary self-control. The latter could be extremely difficult to prove in order to succeed with a defence of pathological criminal incapacity and would depend on the degree to which an accused's conative capacity was impaired by a particular impulse control disorder at the time of the commission of an offence. The defence of pathological criminal incapacity would in all probability not easily succeed based on the presence of an impulse control disorder, as impulse control disorders will not easily meet the threshold requirement of a 'mental illness' or 'mental defect' which is a prerequisite for such defence. As such the defence based on the presence of a particular impulse control disorder will be reserved for exceptional circumstances only.

\section{Diminished Criminal Capacity}

South African criminal law does not, as yet, have a specific defence of diminished criminal capacity. The principle of diminished criminal capacity or responsibility is, however, 
enshrined in s 78(7) of the CPA. Section 78(7) in essence provides that if a court finds that an accused was criminally responsible, but his or her capacity to appreciate the wrongfulness of the act or to act in accordance with such appreciation was diminished as a result of a mental illness or mental defect, the court shall have regard to such diminished responsibility during sentencing. ${ }^{85}$ A person may very well suffer from a mental illness or mental defect but may still be able to appreciate the wrongfulness of his or her act or to act in accordance with such appreciation even if one of these capacities was severely diminished at the time of the commission of the crime. Diminished criminal capacity will not exonerate an accused, but will serve in mitigation of sentence. In determining whether a finding of diminished criminal capacity should be rendered, a court will inadvertently turn to specialist psychiatric evidence in conjunction with all the other relevant information. ${ }^{86}$ Within the framework of impulse control disorders, accused persons suffering from such mental disorders could also rely on $\mathrm{s} 78(7)$ in mitigation of sentence provided that it is established that the individual's capacity to appreciate the wrongfulness of the act or to act in accordance with such appreciation was diminished as a result of suffering from a particular impulse disorder.

This section could prove to be the most viable in cases dealing with impulse control disorders as it is clear that these disorders could diminish an accused's ability or capacity of acting in accordance with an appreciation of the wrongfulness of an act. However, such diminished responsibility will still depend on the existence of a mental illness or mental defect at the time of the commission of the offence. It is a pity that this section was not explored in the Wasserman or Nel decisions, as it could have provided an alternative approach to the role of impulse control disorders on the criminal responsibility of an accused. Diminished criminal capacity will, however, only serve in mitigation and will not lead to exoneration.

\section{Conclusion}

Constructing a defence of pathological criminal incapacity founded on the presence of an impulse control disorder at the time of the commission of the offence remains a controversial issue facing numerous medicolegal issues. In the South African context the defence of pathological criminal incapacity has not been addressed within the ambit of impulse control disorders. The diagnostic features of the impulse control disorders included in the DSM-5 indicate clearly that these disorders could become relevant within the context of the insanity defence, but will be successful in exceptional circumstances only. Given the consequences flowing from a finding of not guilty by reason of insanity it is more likely than not that accused persons will avoid this avenue. Diminished criminal capacity as provided for in s 78(7) could prove to be of more help in situations dealing with impulse control disorders. A finding of diminished criminal capacity will accordingly then be considered in terms of mitigation of sentence. The limited cases that have dealt with pathological gambling indicate that courts will approach these cases with caution. In terms of sentencing, a court will apply a holistic approach and view such disorders in conjunction with all the other facts and circumstances of the case in order to ascertain whether there are substantial and compelling circumstances justifying the imposition of a lesser sentence than ordained in the Act. 
The effect and impact that impulse control disorders had on an accused at the time of the commission of an offence can, however, only be assessed by trained psychiatrists. Despite the fundamental need for expert evidence by forensic experts in cases of this nature, various questions arise as to the scientific reliability and validity of a diagnosis of impulse control disorder as well as the admissibility of such evidence, that still remain unanswered. The risk of malingering in cases of impulse control disorders further exacerbates the problem. It further remains an undeniable reality that law is not always open and receptive to modern scientific evidence and with the advent of the DSM-5, the position could either improve or worsen.

It is pivotal that psychiatric knowledge is provided when the defence of pathological criminal incapacity is raised. The latter becomes especially important when impulse control disorders are raised in support of such defence. Courts should welcome such evidence to the extent needed to explain the behaviour of the accused at the time of the offence. The medical profession, with specific reference to psychiatry, should however also adhere to the boundaries of psychiatric evidence and remain within the ambit of assessment as opposed to providing conclusory opinions on criminal responsibility. The latter remains essentially a legal prerogative.

\section{Notes}

1. N Walker, Crime and Insanity in England: Vol. 1. The Historical Perspective (Edinburgh University Press 1968) as quoted in NJ Finkel, Insanity on Trial (Plenum Press, New York 1988) 10.

2. Facts obtained from JE Grant, Impulse Control Disorders: A Clinician's Guide to Understanding and Treating Behavioral Addictions (WW Norton \& Company, New York 2008) ix-x.

3. CR Snyman, Criminal Law (6th edn, LexisNexis, South Africa 2014) 164-75; CR Snyman, Strafreg (6th edn, LexisNexis, South Africa 2012) 167-84; J Burchell and J Milton, Principles of Criminal Law (3rd edn, Juta, South Africa 2005) 348-60; SZ Kaliski, Psycholegal Assessment in South Africa (OUP, South Africa 2006) 93-110, 237-49; C Tredoux et al, Psychology and Law (Juta, South Africa 2005) 384-410; SA Strauss, Doctor, Patient and the Law: A Selection of Practical Issues (3rd edn, Van Schaik, South Africa 1991) 121-35; E Du Toit et al, Commentary on the Criminal Procedure Act (Juta, Durbanville, South Africa 2012) 13-1-13-30; R Slovenko, Psychiatry and Criminal Culpability (Wiley, Chapman and Hall, New York 1995) 1-66; R Slovenko, Psychiatry in Law/Law in Psychiatry (Brunner Routledge, New York 2002) 187-290; CR Bartol, Criminal Behaviour: A Psychosocial Approach (Prentice Hall 1991) 143-71; CR Bartol and A Bartol, Criminal Behavior: A Psychological Approach (Prentice Hall, Upper Saddle River 2005) 187-235; GB Melton, J Petrilla, NG Poythress and C Slobogin, Psychological Evaluations for the Courts (Guilford Press, New York 2007) 201-266; PHJ Van Rensburg, T Verschoor and JL Snyman, 'Psigiatriese en juridiese aspekte van die begrip geestesongesteldheid' [Psychiatric and legal aspects pertaining to the concept of mental illness] (1983) 8 Journal of Juridical Sciences 162-71; GA Dolin, 'Healer or Executioner? The Proper Role of a Psychiatrist in a Criminal Justice System' (2003) Journal of Law and Health 169-216; J Mihalik, 'Legal Aspects of Forensic Psychiatry in South Africa' (1992) 11 Medicine 
and Law 239-48; W Bromberg, 'Psychiatrists in Court: The Psychiatrist's View' (1969) American Journal of Psychiatry 1342-47; FFW Van Oosten, 'The Insanity Defence: Its Place and Role in the Criminal Law' (1990) 3 South African Journal of Criminal Justice 1-9; J Plomp, 'Die psigiater en die vasstelling van Toerekeningsvatbaarheid' [The psychiatrist and the assessment of criminal capacity] (1983) 8 Journal of Juridical Sciences 154-61.

4. Sections 77-79 of the Criminal Procedure Act 51 of 1977 (hereinafter referred to as the 'CPA'. See also BT Gilmer, DA Louw and T Verschoor, 'Law and Psychology: An Exploration of the Conceptual Interface' (1997) 10 South African Journal of Criminal Justice 19.

\section{Strauss (n 3) 127-28.}

6. A Stone, 'The Insanity Defence on Trial' (1982) Hospital and Community Psychiatry 394414.

7. American Psychiatric Association, Diagnostic and Statistical Manual of Mental Disorders (5th edn, 2013) (hereafter 'DSM-5'). See also American Psychiatric Association, Diagnostic and Statistical Manual of Mental Disorders (4th edn, Washington 1994) (hereafter 'DSMIV'); American Psychiatric Association, Diagnostic and Statistical Manual of Mental Disorders - DSM-IV-TR (4th edn, Text Revision, Washington 2000) (hereafter 'DSM-IV-TR'). The DSM-5 defines mental disorders as follows:

A mental disorder is a syndrome characterized by clinically significant disturbance in an individual's cognition, emotion regulation, or behavior that reflects a distinction in the psychological, biological, or developmental processes underlying mental functioning. Mental disorders are usually associated with significant distress or disability in social, occupational, or other important activities. An expectable or culturally approved response to a common stressor or loss, such as the death of a loved one, is not a mental disorder. Socially deviant behavior (e.g., political, religious, or sexual) and conflicts that are primarily between the individual and society are not mental disorders unless the deviance or conflict results from a dysfunction in the individual, as described above.

The DSM- 5 cautions in respect of the use of this definition within legal contexts by stating as follows:

This definition of mental disorder was developed for clinical, public health, and research purposes. Additional information is usually required beyond that contained in the DSM- 5 diagnostic criteria in order to make legal judgments on such issues as criminal responsibility, eligibility for disability compensation, and competency.

Accordingly, despite clarity being provided to an extent pertaining to the definition of mental disorder, its applicability within the ambit of assessing criminal responsibility remains an open question.

8. DSM-5 ( $\mathrm{n}$ 7) 25 . It is interesting to note that the cautionary statement contained in the DSM-5 is more elaborate than the one provided for in the DSM-IV and the revised DSM-IVTR where the caveat read as follows: 
The purpose of the DSM-IV is to provide clear descriptions of diagnostic categories in order to enable clinicians and investigators to diagnose, communicate about, study, and treat people with various mental disorders. It is to be understood that inclusion here, for clinical and research purposes, of a diagnostic category such as Pathological Gambling or Paedophilia does not imply that the condition meets legal or other non-medical criteria for what constitutes mental disease, mental disorder, or mental disability. The clinical and scientific considerations involved in categorization of these conditions as mental disorders may not be wholly relevant to legal judgments, for example, that take into account such issues as individual responsibility, disability determination, and competency. (Emphasis added).

9. Emphasis added.

10. FG Moeller, ES Barratt, DM Dougherty, JM Schmitz and ACT Swann, 'Psychiatric Aspects of Impulsivity' (2001) 158 American Journal of Psychiatry 1783-93; see also Grant (n 2) 1. See also S Penney, 'Impulse Control and Criminal Responsibility: Lessons from Neuroscience' (2012) International Journal of Law and Psychiatry 99-103.

11. DSM-IV-TR (n 7) 663. See also Grant (n 2) 1. See also M Stoll, 'Miles to Go Before we Sleep: Arizona's Guilty Except Insane Approach to the Insanity Defense and its Unrealized Promise' (2009) Georgetown Law Journal 1768, 1791.

12. See In addition, t supra note 7 at 481 . See also S Reilly and N Smith, The Evolving Definition of Pathological Gambling in the DSM-5, National Center for Responsible Gambling <www.ncrg.org > (accessed 19 March 2015). See also R Stinchfield, 'Reliability, Validity, and Classification Accuracy of a Measure of DSM-IV Diagnostic Criteria for Pathological Gambling' (2003) 160 (1) American Journal of Psychiatry 180-82.

13. Stoll (n 11) 1793.

14. Stoll (n 11) 1793.

15. Stoll (n 11) 1793.

16. DSM-IV-TR (n 7) 663.

17. DSM-5 (n 7) 461-79.

18. DSM-5 (n 7) 585.

19. For purposes of this discussion the disorders known as oppositional defiant disorder, conduct disorder and antisocial personality disorder will not be addressed. It is notable that the disorder known as trichotillomania which is characterised by recurrent pulling out of one's hair for pleasure or relief of tension was not included in the current DSM-5 as an impulse control disorder. 
20. DSM-IV-TR (n 7) 671. See also A Frances, Essentials of Psychiatric Diagnosis: Responding to the Challenge of DSM-5 (Guilford Press, New York 2013) 138-39. The diagnostic criteria for pathological gambling is set forth in the DSM-IV-TR and provides as follows:

\section{Diagnostic criteria for 312.31 Pathological Gambling}

A. Persistent and recurrent maladaptive gambling behavior as indicated by five (or more) of the following: (1) is preoccupied with gambling (e.g., preoccupied with reliving past gambling experiences, handicapping or planning the next venture, or thinking of ways to get money with which to gamble); (2) needs to gamble with increasing amounts of money in order to achieve the desired excitement; (3) has repeated unsuccessful efforts to control, cut back, or stop gambling; (4) is restless or irritable when attempting to cut down or stop gambling; (5) gambles as a way of escaping from problems or of relieving adysphoric mood (e.g., feelings of helplessness, guilt, anxiety, depression); (6) after losing money gambling, often returns another day to get even ('chasing' one's losses); (7) lies to family members, therapist, or others to conceal the extent of involvement with gambling; (8) has committed illegal acts such as forgery, fraud, theft, or embezzlement to finance gambling; (9) has jeopardized or lost a significant relationship, job, or educational or career opportunity because of gambling; (10) relies on others to provide money to relieve a desperate financial situation caused by gambling; $B$. The gambling behavior is not better accounted for by a Manic Episode.

21. DSM-IV-TR (n 7) 671.

22. DSM-IV-TR (n 7) 671.

23. DSM-IV-TR (n 7) 671.

24. DSM-IV-TR (n 7) 671.

25. DSM-IV-TR (n 7) 671.

26. Grant (n 2) 3.

27. Frances (n 20) 139.

28. See the criteria provided for pathological gambling in note 20 . The diagnostic criteria provided for gambling disorder contained in the DSM-5 provide for the following:

Gambling Disorder Diagnostic Criteria 312.31 (F63.0)

A. Persistent and recurrent problematic gambling behaviour leading to clinically significant impairment or distress, as indicated by the individual exhibiting four (or more) of the following in a 12-month period: 1 . Needs to gamble with increasing amounts of money in order to achieve the desired excitement. 2. Is restless or irritable when attempting to cut down or stop gambling. 3. Has made repeated unsuccessful efforts to control, cut back, or stop gambling. 4. Is often preoccupied with gambling (e.g., having persistent thoughts of reliving past gambling experiences, handicapping or planning the next venture, thinking of 
ways to get money with which to gamble). 5. Often gambles when feeling distressed (e.g., helpless, guilty, anxious, depressed). 6 . After losing money gambling, often returns another day to get even ('chasing' one's losses). 7. Lies to conceal the extent of involvement with gambling. 8. Has jeopardized or lost a significant relationship, job, or educational or career opportunity because of gambling. 9. Relies on others to provide money to relieve desperate financial situations caused by gambling. B. The gambling behaviour is not better explained by a manic episode.

29. DSM-5 (n 7) 586-87.

30. SA Tovino, 'Last in the Shuffle: How Health and Disability Laws Hurt Disordered Gamblers' (2014) 89 Tulane Law Review 191-200.

31. DSM-5 (n 7) 585.

32. Tovino (n 30) 191-93.

33. DSM-5 (n 7) 466-69. The diagnostic criteria for intermittent explosive behaviour as contained in the DSM-5 include the following:

Intermittent Explosive Disorder Diagnostic Criteria 312.34 (F63.81)

A. Recurrent behavioral outbursts representing a failure to control aggressive impulses as manifested by either of the following: 1. Verbal aggression (e.g., temper tantrums, tirades, verbal arguments or fights) or physical aggression toward property, animals, or other individuals, occurring twice weekly, on average, for a period of 3 months. The physical aggression does not result in damage or destruction of property and does not result in physical injury to animals or other individuals. 2. Three behavioral outbursts involving damage or destruction of property and/or physical assault involving physical injury against animals or other individuals occurring within a 12-month period. B. The magnitude of aggressiveness expressed during the recurrent outbursts is grossly out of proportion to the provocation or to any precipitating psychosocial stressors. C. The recurrent aggressive outbursts are not premeditated (i.e., they are impulsive and/or anger-based) and are not committed to achieve some tangible objective (e.g., money, power, intimidation). D. The recurrent aggressive outbursts cause either marked distress in the individual or impairment in occupational or interpersonal functioning, or are associated with financial or legal consequences. E. Chronological age is at least 6 years (or equivalent developmental level). $F$. The recurrent aggressive outbursts are not better explained by another mental disorder (e.g., major depressive disorder, bipolar disorder, disruptive mood dysregulation disorder, a psychotic disorder, antisocial personality disorder, borderline personality disorder) and are not attributable to another medical condition (e.g., head trauma, Alzheimer's disease) or to the physiological effects of a substance (e.g., a drug of abuse, a medication). For children ages 6-18 years, aggressive behavior that occurs as part of an adjustment disorder should not be considered for this diagnosis.

It is interesting to note that the DSM-5 has expanded the criteria for this disorder. See also the DSM-IV-TR, 667 where the criteria for this disorder are provided as follows: 
Diagnostic criteria for 312.34 Intermittent Explosive Disorder

A. Several discrete episodes of failure to resist aggressive impulses that result in serious assaultive acts or destruction of property. B. The degree of aggressiveness expressed during the episodes is grossly out of proportion to any precipitating psychosocial stressors. C. The aggressive episodes are not better accounted for by another mental disorder (e.g., Antisocial Personality Disorder, Borderline Personality Disorder, a Psychotic Disorder, a Manic Episode, Conduct Disorder, or Attention-Deficit/Hyperactivity Disorder) and are not due to the direct physiological effects of a substance (e.g., a drug of abuse, a medication) or a general medical condition (e.g., head trauma, Alzheimer's disease).

See also Grant (n 2) 8.

34. DSM-5 (n 7) 467. See also Grant (n 2) 8.

35. DSM-5 (n 7) 467.

36. DSM-5 (n 7) 467.

37. DSM-5 (n 7) 467.

38. DSM-5 (n 7) 467.

39. DSM-5 (n 7) 468.

40. DSM-5 (n 7) 476; Grant (n 2) 6-7. The diagnostic criteria in the DSM-5 for pyromania is enumerated as follows:

Pyromania Diagnostic Criteria 312.33 (F63.1)

A. Deliberate and purposeful fire setting on more than one occasion. B. Tension or affective arousal before the act. C. Fascination with, interest in, curiosity about, or attraction to fire and its situational contexts (e.g., paraphernalia, uses, consequences). D. Pleasure, gratification, or relief when setting fires, or when witnessing or participating in their aftermath. E. The fire setting is not done for monetary gain, as an expression of sociopolitical ideology, to conceal criminal activity, to express anger or vengeance, to improve one's living circumstances, in response to a delusion or a hallucination, or as a result of impaired judgment (e.g., in major neurocognitive disorder, intellectual disability [intellectual developmental disorder], substance intoxication). F. The fire setting is not better explained by conduct disorder, a manic episode, or anti-social personality disorder.

41. DSM-5 (n 7) 476.

42. DSM-5 (n 7) 476.

43. DSM-5 (n 7) 478; Grant (n 2) 4. Interestingly, Grant notes that as early as 1816, Andre Matthey, a Swiss physician, made use of the word klopemanie (derived from the Greek words kleptein which means 'to steal' and mania which refers to mental illness, in order to 
refer to the behaviour of a group of thieves that would impulsively steal worthless or unnecessary items. In 1883 two French physicians, Jean Ettienne Esqurrol and CC Marc, changed the term to kleptomania. The diagnostic criteria for kleptomania is enunciated as follows in the DSM-5:

Kleptomania Diagnostic Criteria 312.32 (F63.2)

A. Recurrent failure to resist impulses to steal objects that are not needed for personal use or for their monetary value. B. Increasing sense of tension immediately before committing the theft. C. Pleasure, gratification, or relief at the time of committing the theft. D. The stealing is not committed to express anger or vengeance and is not in response to a delusion or a hallucination. E. The stealing is not better explained by conduct disorder, a manic episode, or antisocial personality disorder.

See also LF Lowenstein, 'Understanding Impulse' (2010) Criminal Law \& Justice Weekly 779780 where it is noted that individuals suffering from kleptomania often are unaware of their condition and only when they are apprehended does it become clear that they are suffering from this disorder. Lowenstein notes the following ( $p$ 779):

Kleptomaniacs find it almost impossible to control their urge to steal and are not necessarily antisocial or suffer from manic behaviour. Their main problem is an inability to control their impulses.

44. DSM-5 (n 7) 478.

45. DSM-5 (n 7) 478.

46. DSM-5 (n 7) 479. See also Frances (n 20) 142-43.

47. Section 78(1) of the Act reads as follows:

78 Mental illness or mental defect and criminal responsibility: (1) A person who commits an act or makes an omission which constitutes an offence and who at the time of such commission or omission suffers from a mental illness or mental defect which makes him or her incapable - (a) of appreciating the wrongfulness of his or her act or omission; or (b) of acting in accordance with an appreciation of the wrongfulness of his or her act or omission, shall not be criminally responsible for such act or omission.

48. Snyman (n 3) 170; Burchell and Milton (n 3) 373; Strauss (n 3) 130; Van Oosten (n 3) 1-9; Du Toit et al (n 3) 13-18.

49. Snyman (n 3) 171.

50. Snyman (n 3) 171.

51. Snyman (n 3) 172; Burchell and Milton (n 3) 377. 
52. Snyman (n 3) 173; Burchell and Milton (n 3) 380-81; Du Toit et al (n 3) 13-14. See also A Landman and W Landman, A Practitioner's Guide to the Mental Health Care Act (Juta 2014) 143-66.

53. Snyman (n 3) 173; Burchell and Milton (n 3) 381.

54. A Africa, 'Psychological Evaluations of Mental State in Criminal Cases' in Tredoux (n 3) 395. See also S v Kavin 19782 SA 731 (W); S v Mcbride 19794 SA 313 (W).

55. Snyman (n 3) 171; Burchell and Milton (n 3) 374.

56. R Slovenko, 'The Meaning of Mental Illness in Criminal Responsibility' (1984) 5 The Journal of Legal Medicine 1-4.

57. Wasserman v S (2005) JOL 13301 (T). See also M Carnelley, 'S v Wasserman - Is dobbelverslawing ' $n$ wesenlike en dwingende omstandigheid in terme van die Strafregwysigingswet wat ' $n$ geringer vonnis regverdig' [Is gambling addiction a substantial and compelling circumstance justifying a lesser sentence] (2005) 30 (1) Journal of Juridical Science 153-61; SV Carnelley Mand Hoctor, 'Pathological Gambling as a Defence in Criminal Law' (2001) 22 (2) Obiter 379-88.

58. Hereinafter referred to as 'the Act'.

59. At [6].

60. At [6].

61. At [7].

62. At [9].

63. At [13].

64. At [22].

65. See Carnelley, S v Wasserman (n 57) 160.

66. See Carnelley, S v Wasserman (n 57) 160.

67. Nel v S (2007) 4 All SA 709 (SCA).

68. At [4]-[5].

69. At [6].

70. At [7].

71. At [10]. 
72. At [10].

73. At [11].

74. At [12].

75. At [13].

76. At [14]

77. At [15].

78. At [16].

79. At [16]. See also S v Malgas (2001) 3 All SA 220 (2001) (1) SACR 469 (SCA) at [25].

80. At [17].

81. At [20].

82. At [21].

83. See M Carnelley, 'The Role of Pathological Gambling in the Sentencing of a Person Convicted of Armed Robbery: A Comparative Discussion of the South African, Canadian and Australian Jurisdictions'(2008) 3 South African Journal of Criminal Justice 296, where the author notes that the court in Wasserman discussed the issue of pathological gambling referring to both the medical and psychological research on the topic whilst specifically stating that pathological gambling constituted a disease. The latter was indeed a positive aspect of the Wasserman decision as opposed to the Nel decision where the court failed to address this issue. Carnelley correctly submits that the court in Wasserman considered all the mitigating and aggravating circumstances in ultimately reaching the finding that the prescribed minimum sentence was shockingly inappropriate. It could accordingly be argued that the criticism by the Appellate division of the Wasserman judgement was in some respects harsh. As Carnelley argues, the court could have provided a more detailed analysis of foreign jurisprudence.

84. Carnelley, 'The Role of Pathological Gambling' (n 83) 304.

85. Burchell and Milton (n 3) 400-402; Snyman (n 3) 170-71; Kaliski (n 3) 105. See also $S v$ Mnisi 20092 SACR 227 (SCA).

86. T Zabow, 'Psychiatric Evidence in Extenuation: Assessment and Testimony in Homicide Defendants' (1989) 8 Medicine and Law 631-39. See also Stoll (n 11) 1793 where he argues, albeit within the context of Arizona, that impulse control disorders should be included within the purview of the insanity defence. The author states that behavioural science and specifically the field of psychiatry are making strides in proving that impulse control disorders are 'real' disorders or syndromes with biological origins which render their victims unable to resist and control internal urges. According to Stoll, research indicates that the 
impulsivity which is the salient feature of impulse control disorders correlates with both neurochemical and neuropsychological abnormalities in individuals. Accordingly, individuals with impulse control disorders have been found to have different neuropsychological characteristics as opposed to other populations. 